\title{
ODE AUX PARAPLUIES
}

Avez-vous jamais pris un parapluie pour abriter vos rêves?

Un parapluie est bien plus confortable qu'une maison, surtout s'il pleut fort.

Un minuscule abri fait plus dense vos rêves, surtout si c'est un parapluie troué d'étoiles.

$J ' a i$ connu de vieilles gens qui ne marchaient jamais sans parapluie ouvert. Vous devinez pourquoi. . ils vivent du passé, et protègent ainsi leurs souvenirs.

Un parapluie a toujours une histoire: il peut se perdre, se retrouver, recueillir les chuchotements des amoureux, cacher la moitié d'un monde. C'est pourquoi les parapluies usés sont toujours les plus attendrissants. Un parapluie est bien plus confortable qu'un soleil: il permet de recueillir une intimité que ne partage jamais le ciel bleu. Et vos rêves restent frais même si la marche est longue.

Si j'êtais homme d'affaires, ce n'est ni à Amsterdam, ni à Bruges que je vendrais mes parapluies, mais en Equateur, dans les plaines tropicales, où rien ne vous protège contre l'agression du "beau temps." Vous feriez des poètes de bien de têtes chaudes, dé casseurs, de bavards qui apprendraient à se taire sous le recueillement d'un toit plein d'idées.

\section{Jean-Claude Muller}

The University of Kansas 